\title{
Redundant Serial Industrial Robots Class-Structural Synthesis and Useful Configuration
}

\author{
Ionel Staretu ${ }^{1,2}$ \\ ${ }^{1}$ Departement of Product Design, Mechatronics and Environment, Transilvania University of Brasov \\ 2 Technical Science Academy of Romania
}

\section{Article Info}

Received Dec 12, 2018

\section{Keyword:}

Industrial serial robot;

Redundant;

Structural synthesis;

Kinematic chain;

Degree of mobility

\begin{abstract}
For the first, the industrial serial robots can be classified according the number of mobility degrees or independent movements, the number of independent kinematic axes, the shape of the workspace, the value of the useful load, the precision of touching a predetermined point, etc. The number of degrees of mobility directly determines the structure of the kinematic chain corresponding to the robot and implicitly its construction, functionality and utility. In this paper, we define the class of redundant industrial serial robots. For the redundant industrial serial robots the structural synthesis method is presented and for each type of representative examples of structures are given.
\end{abstract}

\section{Corresponding Author:}

First Author,

Departement of Product Design, Mechatronics and Environment,

Transilvania University of Brasov,

29 Eroilor Bd., Brasov 500036, Romania, RO.

Email: istaretu@yahoo.com

\section{Introduction}

In present serial industrial robots currently exist in multiple variants in continuous diversification. So far, however, there has not been a classification of serial industrial robots to be useful to both designers and users. Obviously, it is first necessary to establish the main criterion or criteria for classification. By analyzing the technical datasheets of the already manufactured industrial robots, we can note that the main classification criterion is the number of degrees of mobility, respectively the number of independent movements, of independent kinematic axes. Since the structure of a serial industrial robot has been imposed by positioning and targeting an object in a three-orthogonal space, it has initially been determined that the number of independent movements required is 6: 3 independent positioning movements and 3 independent orientation movements [1], [2 ]. Thus, we obtained the structural synthesis of open series cinematic chains with 3 or 6 independent movements. Therefore, the category or class of minimal configuration industrial serial robots has been defined [3] required and sufficient to guide (position and orient) an object in the three-dimensional space relative to an Oxyz three-orthogonal reference system. In time, one or more axes corresponding to independent movements have been added to the minimally configured serial robotic kinematic chains to increase the workspace and enhance the robot functionality. Such structures have been practically obtained individually without systematization and are now available on the industrial robotics market. If we consider the situations where the minimum configurations reach a double number of independent movements, a reasonable degree of redundancy, a second category of industrial robots is defined, namely the category or class of serial redundant industrial robots [4] characterized by 7 to 12 independent movements, respectively, mobility degrees or independent kinematic axes. However, structures with over 12 independent kinematic axes were imagined by the addition of a large or very large serial number of independent movements, 
resulting in robotic trunk-like serial structures [5] or vertebroid [3], obtained by adding, in series, a single cinematic coupling or a limited number of kinematic couplings. These structures with more than 12 independent movements, generating non-degenerated workspaces, form the category or class of hyperredundant serial industrial robots. As a result, it can be considered that depending on the degree of mobility, respectively the number of independent movements - independent active kinematic axes leading to structures that can be characterized by non-degenerated working spaces, there are 3 categories or classes of serial industrial robots, namely 6 independent movements: class of serial industrial robots with minimal configuration, 6 degrees of mobility, respectively 6 independent movements; the class of redundant serial industrial robots characterized by 7 to 12 degrees of mobility, respectively, independent movements and the class of industrial serial hyper-redundant robots with 13 or more degrees of mobility, respectively, independent movements. The paper presents for the first time the general structural synthesis of each class of industrial serial robots and gives suggestive examples of structures specific to each class.

\section{Methodology}

Any serial industrial robot that adds at least a degree of mobility, so an independent movement beyond the 6 necessary minimum mobility degrees, becomes a redundant robot because the additional degree of mobility or degrees of mobility are not necessary for univocal positioning and orientation of an object in the tridimesional space, but only increase the working space and the functionality of the robot by increasing the capacity of accessing additional areas of these structures to structures with minimal configuration [6]. After some time it was considered that robots with more than 6 degrees of mobility, so 6 axes, are not necessary, 7-degree mobility, so 7, 8, even 9-axe structures were made [7], [ 8], [9], [10], [11], [12], [13], [14], [15], [16], without a systematization of the possible variants and implicitly a method of rigorous structural synthesis. In the paper [4] a method of structural synthesis of redundant serial robots has been proposed and described, of which all structures with 7 to 12 degrees of mobility, i.e. 7 to 12 independent kinematic axes, are considered to belong. It is considered that the limitation to 12 degrees of mobility is appropriate because thus, we obtain a double number of degrees of mobility compared to the minimum necessary and sufficient, 6 , type of redundancy encountered frequently in nature too, in living organisms ( 2 eyes, 2 kidneys, 2 lungs, 2 hands, etc.). For the structural synthesis of redundant serial robots, all guiding structures, so positioning chain(PC), are considered, with three degrees of mobility, which are characterized by non-degenerated workspaces and corresponding orientation chains (OC), plus one degree of mobility corresponding to a monomobile kinematic rotation (R) or translation $(\mathrm{T})$ coupling, placed in a perpendicular position $(\perp)$ or parallel $(\|)$ position relative to the PC couplings, respectively the positioning mechanism (PM), or the OC module, respectively the orientation mechanism $(\mathrm{OM})$.

\section{Results}

Thus, for redundant robots with 7 degrees of mobility, i.e. 7 independent kinematic axes, there are structures of the type: $\mathrm{R} \perp(\mathrm{PM})(\mathrm{OM}), \mathrm{R} \|(\mathrm{PM})(\mathrm{OM})$ or $\mathrm{T} \perp(\mathrm{PM})(\mathrm{OM}), \mathrm{T} \|(\mathrm{PM})(\mathrm{OM})$. By highlighting all the possible situations, there are 12 redundant structures with 7 axes: $\mathrm{R} \perp(\mathrm{PM})(\mathrm{OM}), \mathrm{R} \|(\mathrm{PM})(\mathrm{OM}), \mathrm{T} \perp(\mathrm{PM})(\mathrm{OM})$,

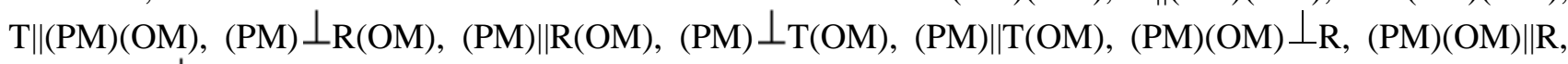
$(\mathrm{PM})(\mathrm{OM}) \perp_{\mathrm{T}},(\mathrm{PM})(\mathrm{OM}) \| \mathrm{T}$. As a result, the 20 positioning structures $(\mathrm{PM})$ characterized by nondegenerated workspaces correspond to $20 * 12=240$ redundant structures with 7 degrees of mobility. In Figure 1 there are two variants of redundant structures with 7 degrees of mobility and 7 independent kinematic axes: $\left.\mathrm{R} \perp_{(\mathrm{R}} \perp_{\mathrm{R}} \perp_{\mathrm{T}}\right)(\mathrm{OM}: \mathrm{R} \perp \mathrm{R} \perp \mathrm{R})$ și $\left.\mathrm{T} \perp_{(\mathrm{R}} \perp_{\mathrm{R}} \perp_{\mathrm{T}}\right)(\mathrm{OM}: \mathrm{R} \perp \mathrm{R} \perp \mathrm{R})$.

Structures with 8 axes are obtain by adding an additional axis of $\mathrm{R}$ or $\mathrm{T}$ in position $\perp_{\text {or }} \|$ to the structures with 7 axes obtained in the previous step, resulting in structures of the type: $R \perp[R \perp(P M)(O M)], R \|[R \perp$ $(\mathrm{PM})(\mathrm{OM})], \mathrm{T} \perp[\mathrm{R} \perp(\mathrm{PM})(\mathrm{OM})], \mathrm{T} \mid[\mathrm{R} \perp(\mathrm{PM})(\mathrm{OM})]$. By highlighting all possible situations of the eight-axis

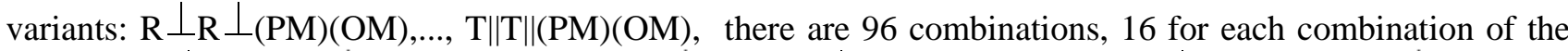
type $(\mathrm{R} / \mathrm{T})(\perp / \|)(\mathrm{R} / \mathrm{T})(\perp / \|)(\mathrm{PM})(\mathrm{OM}),(\mathrm{R} / \mathrm{T})(\perp / \|)(\mathrm{PM})(\perp / \|)(\mathrm{R} / \mathrm{T})(\mathrm{OM}),(\mathrm{R} / \mathrm{T})(\perp / \|)(\mathrm{PM})(\mathrm{OM})(\perp / \|)(\mathrm{R} / \mathrm{T})$, $(\mathrm{PM})(\perp / \|)(\mathrm{R} / \mathrm{T})(\mathrm{OM})(\perp / \|)(\mathrm{R} / \mathrm{T}),(\mathrm{PM})(\perp / \|)(\mathrm{R} / \mathrm{T})(\perp / \|)(\mathrm{R} / \mathrm{T})(\mathrm{OM})$ și $(\mathrm{PM})(\mathrm{OM})(\perp / \|)(\mathrm{R} / \mathrm{T})(\perp / \|)(\mathrm{R} / \mathrm{T})$. 

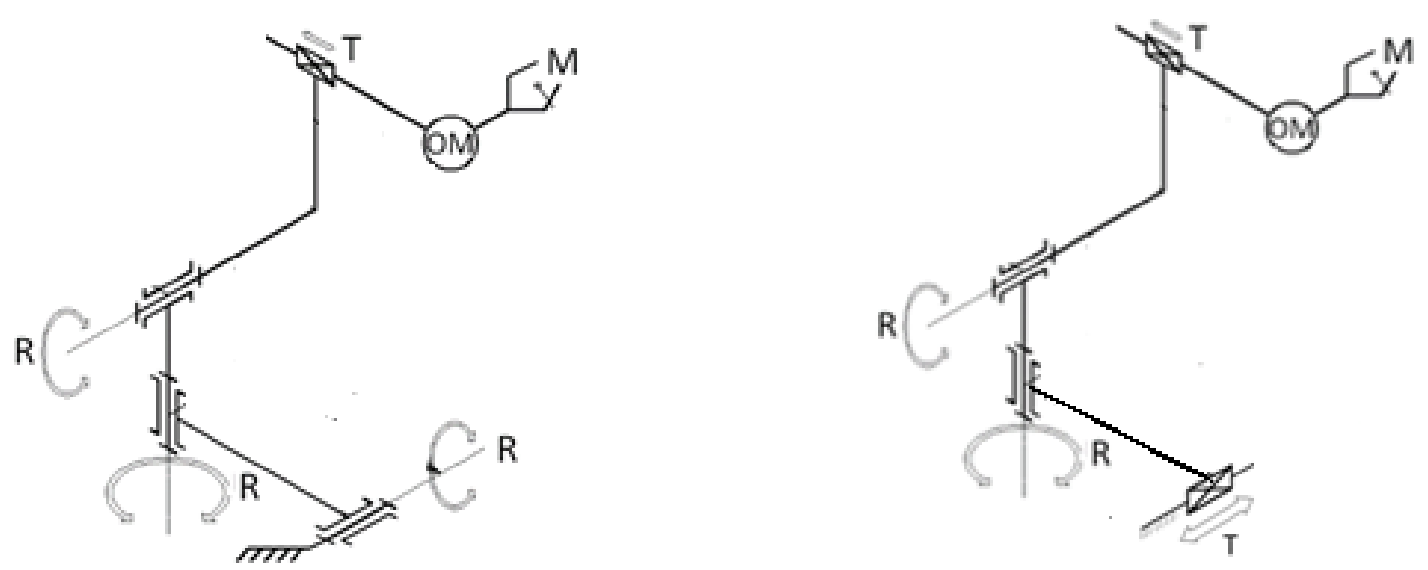

Figure 1: Two variants of redundant structures with 7 degrees of mobility and 7 independent kinematic axes: $\left.\mathrm{R} \perp_{(\mathrm{PM}: \mathrm{R}} \perp_{\mathrm{R}} \perp_{\mathrm{T})(\mathrm{OM}: \mathrm{R}} \perp_{\mathrm{R}} \perp_{\mathrm{R}}\right)$ and $\left.\mathrm{T} \perp_{(\mathrm{PM}: \mathrm{R}} \perp_{\mathrm{R}} \perp_{\mathrm{T})(\mathrm{OM}: \mathrm{R}} \perp_{\mathrm{R}} \perp_{\mathrm{R}}\right)$.

Figure 2 gives two examples of structures with 8 axes of the type: $R \perp R \|\left(R \| R \perp_{R}\right)(O M: R \perp R \perp R)$ and $T$ $\left.\perp_{\mathrm{R} \|(\mathrm{R} \| \mathrm{R}} \perp_{\mathrm{R}}\right)(\mathrm{OM}: \mathrm{R} \perp \mathrm{R} \perp \mathrm{R})$.
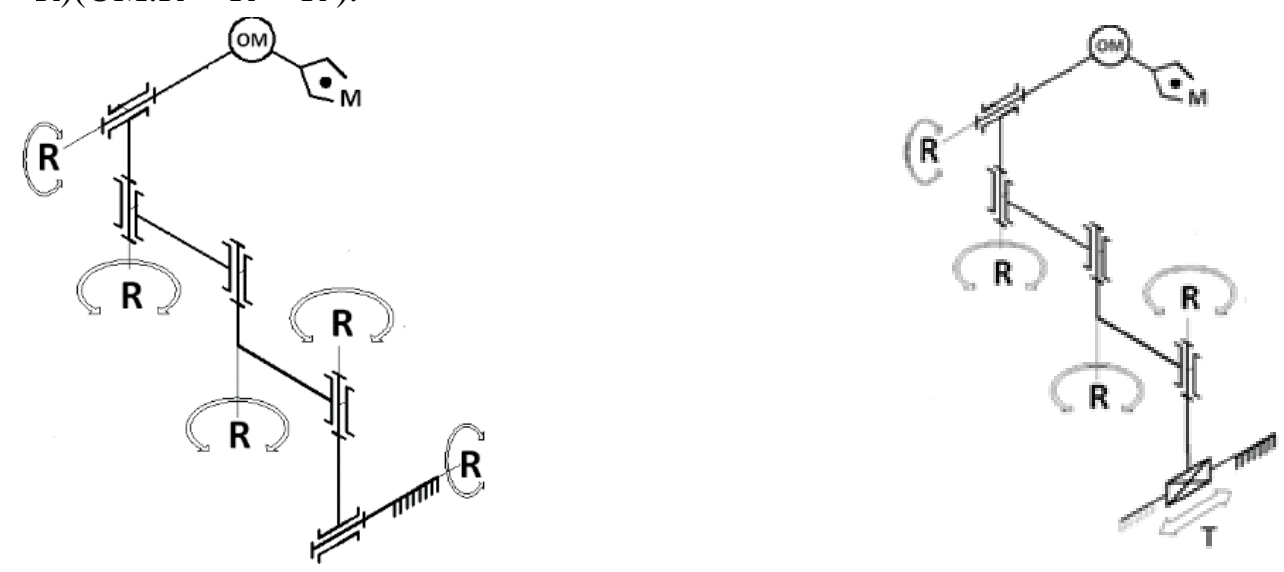

Figure 2: Structures with 8 degrees of mobility- 8 independent axes.

9-axis structures are obtained by adding an additional $\mathrm{R}$ or $\mathrm{T}$ axis in $\perp$ or $\|$ position to structures with 8 axes,

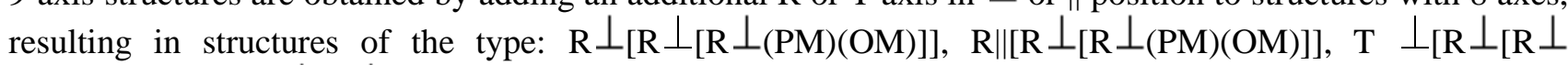
$(\mathrm{PM})(\mathrm{OM})]], \mathrm{T} \|[\mathrm{R} \perp[\mathrm{R} \perp(\mathrm{PM})(\mathrm{OM})]]$. Two examples of nine-axis structures are shown in Figure 3.
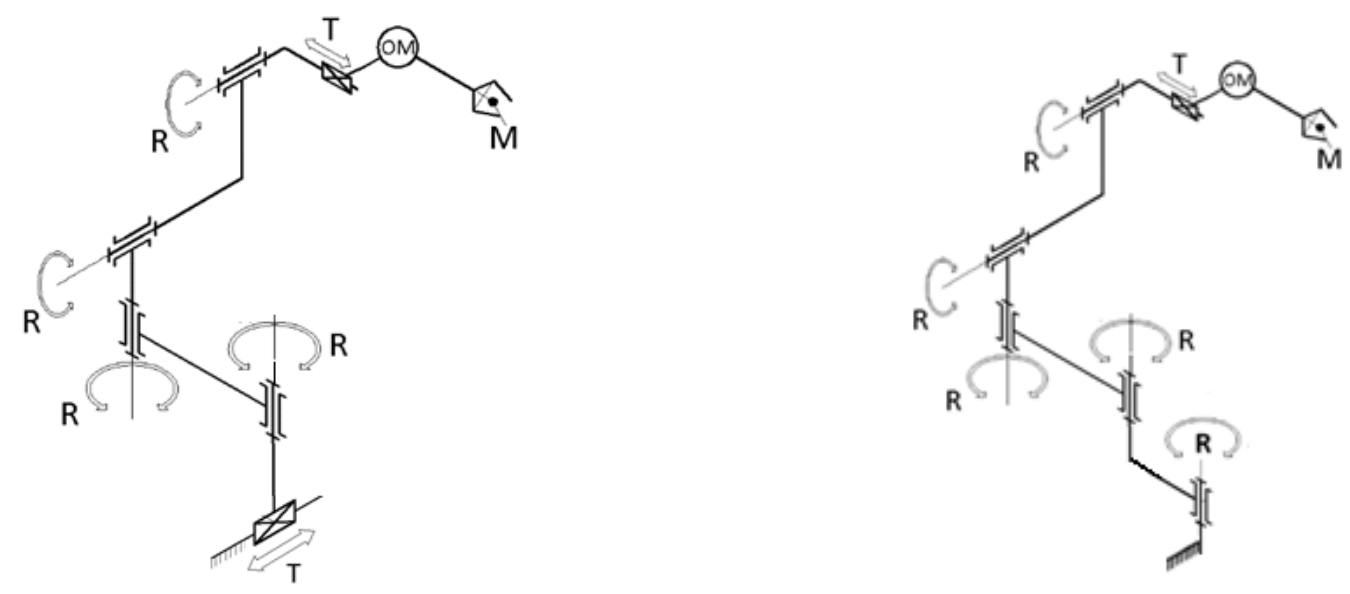

Figure 3: Structures with 9 degrees of mobility- 9 independent axes. 
Structures with 10 axes are obtained by adding an additional axis of $\mathrm{R}$ or $\mathrm{T}$ in position $\perp_{\text {or }} \|$ to structures with 9 axes, resulting in structures of the type: $\left.\mathrm{R} \perp_{[\mathrm{R}} \perp[\mathrm{R} \perp[\mathrm{R} \perp(\mathrm{PM})(\mathrm{OM})]]\right], \mathrm{R} \|\left[\mathrm{R} \perp_{[\mathrm{R}} \perp_{[\mathrm{R}} \perp\right.$ $(\mathrm{PM})(\mathrm{OM})]]]], \mathrm{T} \perp[\mathrm{R} \perp[\mathrm{R} \perp[\mathrm{R} \perp(\mathrm{PM})(\mathrm{OM})]]], \mathrm{T} \|[\mathrm{R} \perp \quad[\mathrm{R} \perp \quad[\mathrm{R} \perp \quad(\mathrm{PM})(\mathrm{OM})]]]$. Figure 4 gives two examples of structures with 10 axes.
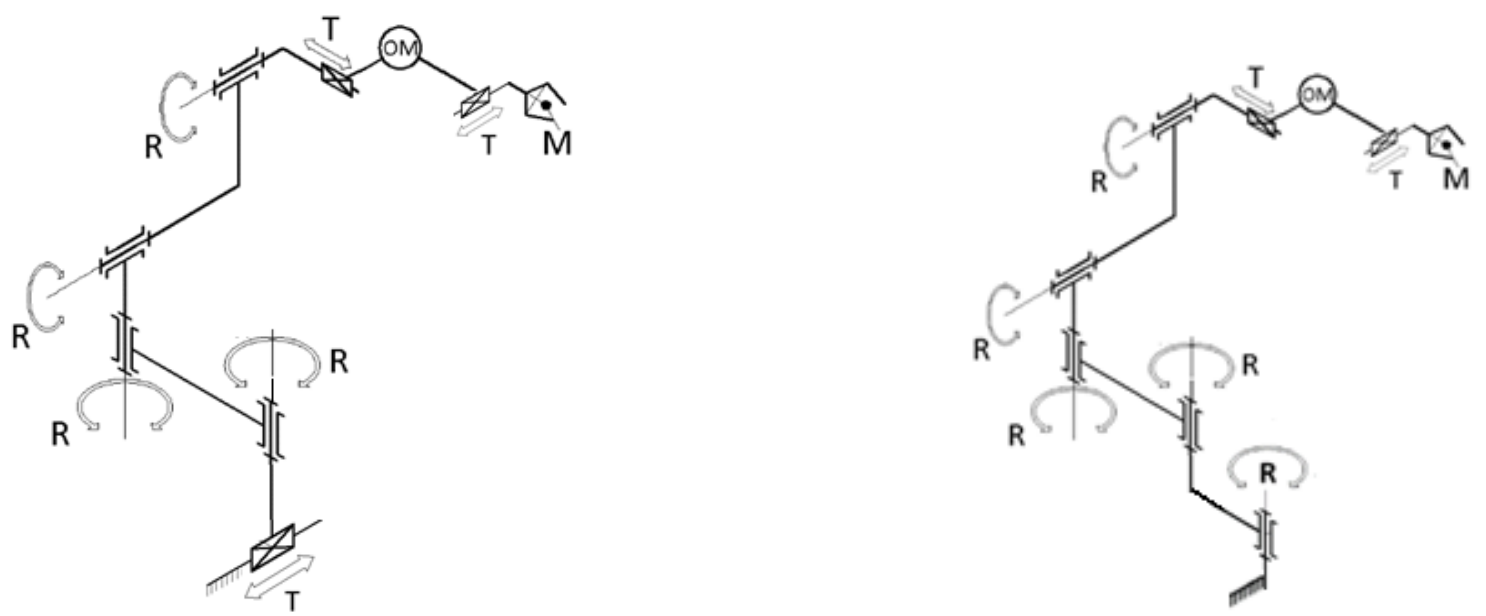

Figure 4: Structures with 10 degrees of mobility - 10 independent axes.

Structures with 11 axes are obtained by adding an additional axis of $\mathrm{R}$ or $\mathrm{T}$ in $\perp_{\text {position }}$ or $\|$ to structures with 10 axes, resulting in structures of the type: $\mathrm{R} \perp_{[\mathrm{R}} \perp_{[\mathrm{R}} \perp_{[\mathrm{R}} \perp_{[\mathrm{R}} \perp_{(\mathrm{PM})(\mathrm{OM})]]]}, \mathrm{R} \|\left[\mathrm{R} \perp_{[\mathrm{R}} \perp_{[\mathrm{R}} \perp_{[\mathrm{R}}\right.$ $\perp(\mathrm{PM})(\mathrm{OM})]]], \mathrm{T} \perp[\mathrm{R} \perp[\mathrm{R} \perp[\mathrm{R} \perp[\mathrm{R} \perp(\mathrm{PM})(\mathrm{OM})]]]], \mathrm{T} \|[\mathrm{R} \perp[\mathrm{R} \perp[\mathrm{R} \perp[\mathrm{R} \perp(\mathrm{PM})(\mathrm{OM})]]]] . \mathrm{In}$ Figure 5 there are two examples of structures with 11 axes.
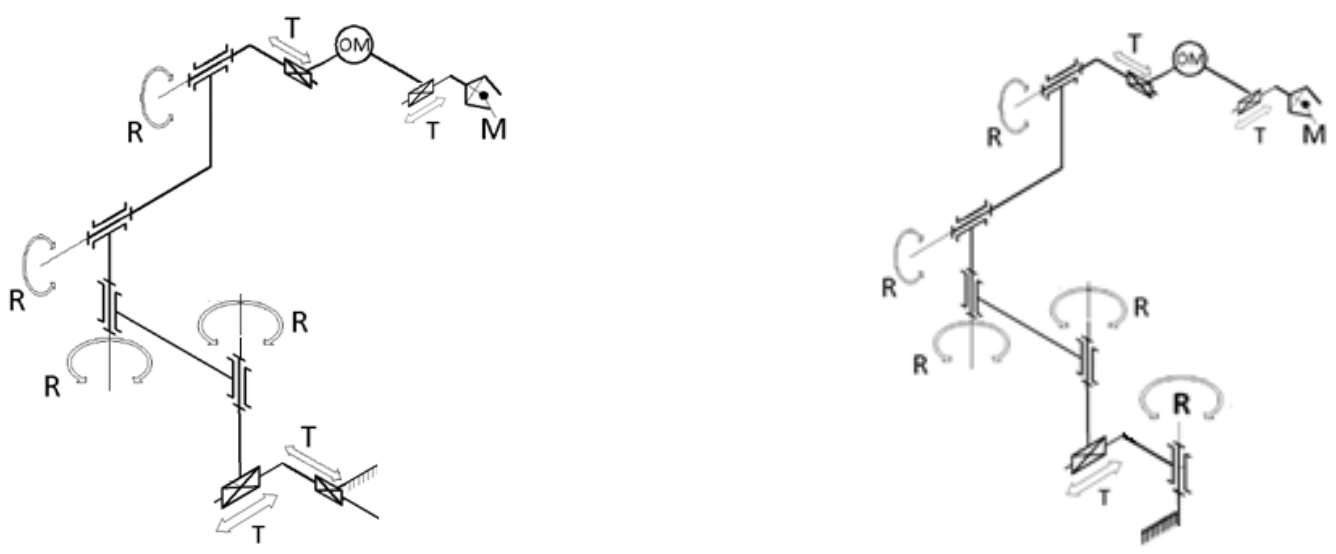

Figure 5: Structures with 11 degrees of mobility - 11 independent axes.

Structures with 12 axes are obtained by adding an additional axis of $\mathrm{R}$ or $\mathrm{T}$ in position $\perp_{\mathrm{or}} \|$ to structures

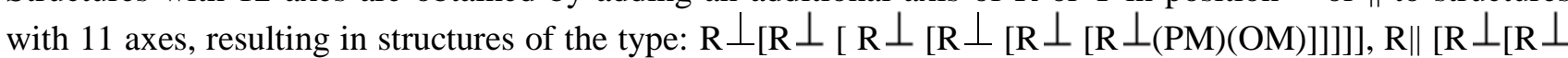
$[\mathrm{R} \perp[\mathrm{R} \perp[\mathrm{R} \perp(\mathrm{PM})(\mathrm{OM})]]]]], \mathrm{T} \perp[\mathrm{R} \perp[\mathrm{R} \perp[\mathrm{R} \perp[\mathrm{R} \perp[\mathrm{R} \perp(\mathrm{PM})(\mathrm{OM})]]]]], \mathrm{T} \|[\mathrm{R} \perp[\mathrm{R} \perp[\mathrm{R} \perp[\mathrm{R} \perp[\mathrm{R}$ $\perp(\mathrm{PM})(\mathrm{OM})]]]]]$. Two examples of structures with 12 axes are given in Figure 6. In the examples given in Figures 1-6, only the axes of the positioning mechanism (PM) and the additional axes are represented with the schematic representation of the orientation mechanism (OM), which contains three axes of perpendicular rotation $\left(\mathrm{R} \perp_{\mathrm{R}} \perp_{\mathrm{R}}\right)$, and adding them the total number of axes specified for each structure is obtained. Also, in the serial redundant robot structures, there are all current variants of robots that can move through translational movements on one to three perpendicular axes if the assembly is considered as a whole and all the axes are commanded by a unitary computing system. 

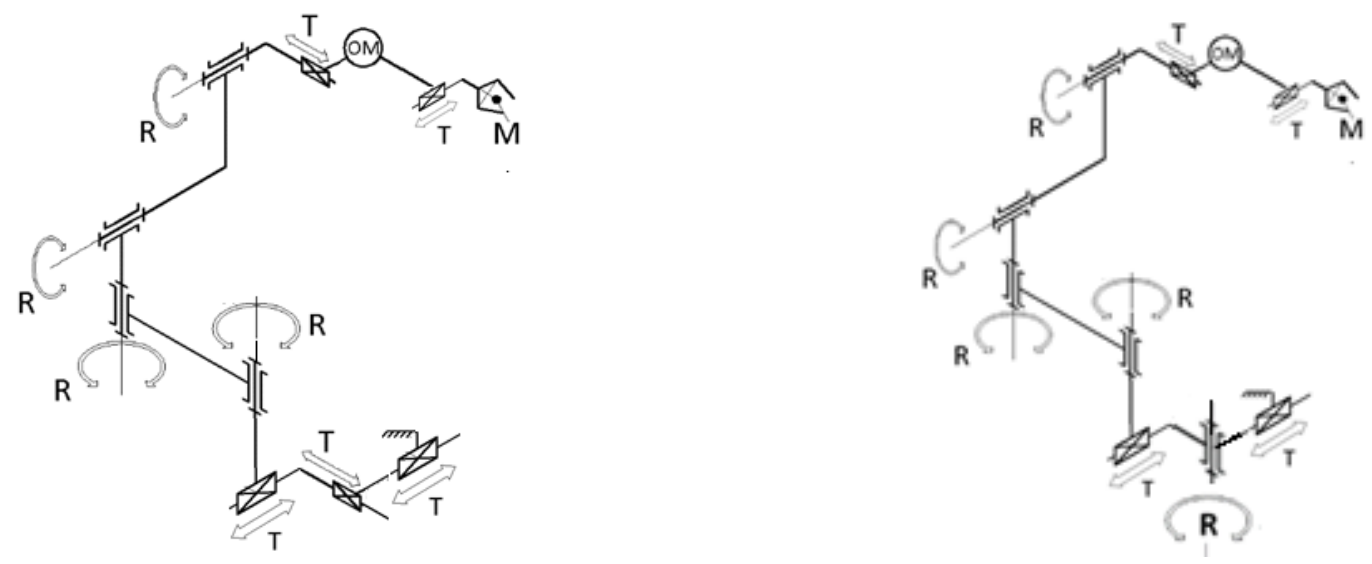

Figure 6: Structures with 12 degrees of mobility - 12 independent axes

\section{Conclusions}

Regarding the aspects presented in this paper, the following conclusions can be drawn:

1. A systematization of the minimum configuration serial robot structures with 6 degrees of mobility was completed in the 1980s, the continuation of such systematization for serial robot structures with 7 or more degrees of mobility was given up, but later such structures have emerged through disparate practical achievements.

2. In this paper the author proposed for the first time the definition of the class of redundant serial robots with 7 to 12 degrees of mobility for which he proposed a method of structural synthesis, which allows highlighting the most useful structures possible.

3. Serial robots with 13 or more degrees of mobility form the class of hyper-redundant robots.

\section{Acknowledgements}

We express our gratitude to the company CLOOS in Germany and its representative in Romania, Timisoara ROBCON company, for supporting our research whose results are presented in part in this paper.

\section{References}

[1] I. Ion, L. Vladareanu, R. Jr. Munteanu and M. Munteanu, "The improvement of structural and real time control performances for MERO modular," Advances in Climbing and Walking Robots, Word Scientific Publishing, pp. 252-263, 2007.

[2] X. J. Wang, X. Wang, H. Yu, H. Wang, L. Lu, L. Vladareanu and O. D. Melinte, "Dynamic analysis for the leg mechanism of a wheel-leg hybrid rescue robot," in UKACC International Conference on Control (CONTROL), Loughborough, UK, pp. $504-508,2014$.

[3] Fl. Dudita, D. Diaconescu and Gr. Gogu, "Linkages mechanisms ( in Romanian)," Bucharest, Editura Tehnica, 1989.

[4] I. Staretu, "Class of redundant serial robots with 7 up to 12 axes-definition, structural synthesis and workspace," in Proceedings of the 6th International Conference Computational Mechanics and Virtual Engineering COMEC 2015(CD), pp. 1-6, 2015.

[5] M. Ivanescu, "On the dynamic control of hyper-redundant manipulators," Advances in Automatic Control, Dordrecht-Kluwer Academic Publishers, pp. 141-158, 2004.

[6] V. Vladareanu, I. Dumitrache, L. Vladareanu, S. I. Sacală, G. Tonţ and A. M. Moisescu, "Versatile Intelligent Portable Robot Control Platform Based on Cyber Physical Systems Principles," Studies in Informatics and Control, vol. 24 (4), pp. 409-418, 2015.

[7] S. Brell-Cokcan, M. Reis, H. Schmiedhofer and J. Braumann, "Digital Design to Digital Production: Flank Milling with a 7-Axis Robot and Parametric Design," in Proceedings of the 27th eCAADe Conference, pp. 323-330, 2009. 
[8] R. Qi, T.L. Lam, H. Qian and Y. Xu, "Arc tracking on an eight-axis robot system," in Proceedings IEEE International Conference on Robotics and Biomimetics (ROBIO)," pp. 678-683, 2011.

[9] J. Wang, Y. Li and X. Zhao, "Inverse Kinematics and Control of a 7-DOF Redundant Manipulator Based on the Closed-Loop Algorithm," International Journal of Advanced Robotic Systems, vol. 7(4), pp. 1-9, 2010 .

[10] Information on: www.foodengineeringmag.com/.../seven-ax.

[11] Information on: www.motoman.co.

[12] Information on: www.yaskawa.co.jp/en/.../robotics/01.html.

[13] Information on: www.ragroup.com.au/robots/.../sda_sia_seri....

[14] Information on: www.cloos.de/QIROX/.../roboter/.../index.p...

[15] Information on: www.densorobotics.com/news/34.

[16] Information on: www.directindustry.com > ... > Articulated robot.

\section{BIBLIOGRAPHY OF AUTHOR}

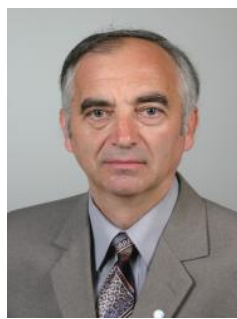

Ionel Staretu was born in Rusavat, Buzau, Romania, on April 16, 1957. He is a graduate of the TCM Faculty of the Transylvania University of Brasov (1983), Romania. He obtained a PhD degree in Industrial Robots specialization in 1995. Specializations in: Tribology (Transylvania University of Brasov-1990), Robotique et Productique (INSTN of Saclay, France-1992/1993), Organization Management (IAI and Transylvania University of Braşov -1999/2000), Quality Management (2003) and Quality Audit (2004) at the Transilvania University of Brasov. Since 2003, he is an Outsourced Technical Expert and Certified Consultant by CERTEXPERT Bucharest and A.E.X.E.A. Paris.

He has been working at the Department of Product Design and Robotics since 1985, currently the Department of Product Design, Mechatronics and Environment at the Transylvania University in Brasov. He published: 6 books (Gripping systems in USA, 2011); Sisteme de prehensiune, Romania, 2006, 2010; Elements of medical robotics and prosthesis, Romania, 2005), 5 didactic works and over 220 scientific articles in the country and abroad. He is the author or co-author of 11 patents. He has helped solve over 28 national and international scientific research grants (at 4 as grant director).

Prof. Staretu is the President of the Brasov Branch of the Romanian Society of Robotics, vice president of AGIR Braşov Branch, member of ARoTMM and expert in Robotics of the Academic Society of Romania, member CRIFŞTRomanian Academy; member of the Committee of Publishers in Romania and abroad (USA, Serbia, India) and Scientific Committees at national and international scientific events. $\mathrm{He}$ is a $\mathrm{PhD}$ supervisor in the field of Industrial Engineering. Since 2017 he is a correspondent member of the Academy of Technical Sciences of Romania-ASTR. 